\title{
Total energy expenditure in children with obstructive sleep apnoea syndrome
}

\author{
R.M. Bland*, S. Bulgarelli, ${ }^{\#}$, J.C. Ventham*, D. Jackson*, J.J. Reilly", J.Y. Paton*
}

Total energy expenditure in children with obstructive sleep apnoea syndrome. R.M. Bland, S. Bulgarelli, J.C. Ventham, D. Jackson, J.J. Reilly, J.Y. Paton. (C)ERS Journals Ltd 2001.

ABSTRACT: Childhood obstructive sleep apnoea syndrome (OSAS) acts as a check on growth and nutritional status. An increase in sleeping energy expenditure has been proposed as a possible mechanism, but to date, no studies have determined whether energy requirements (total energy expenditure; TEE) are raised in OSAS. The aim of this study was to test the hypothesis that OSAS is associated with increased TEE.

Eleven children (mean \pm SD 5.8 \pm 2.2 yrs of age) with OSAS confirmed by nocturnal polysomnography were each matched with a pair of healthy controls $(n=22)$ of the same age and sex. TEE was measured using the doubly-labelled water method in all subjects. In 10/11 patients TEE was also measured after adenotonsillectomy and changes in TEE assessed.

There was no significant difference in TEE between patients (mean \pm SD $\left.325 \pm 44 \mathrm{~kJ} \cdot \mathrm{kg}^{-1} \cdot \mathrm{day}^{-1}\right)$ and controls $\left(339 \pm 48 \mathrm{~kJ} \cdot \mathrm{kg}^{-1} \cdot \mathrm{day}^{-1}\right)$, nor between patients and age- and sex-specific literature data on TEE, using the doubly-labelled water method. Differences in TEE within patients, before versus after surgery, were minor and not statistically significant.

This study does not support the hypothesis that obstructive sleep apnoea syndrome in childhood is associated with increased energy requirements, and suggests that alternative explanations for the effect of this syndrome on growth and energy balance should be sought.

Eur Respir J 2001; 18: 164-169.
University of Glasgow, Depts of *Child Health and \#Human Nutrition, Yorkhill Hospitals, Glasgow, UK, and 'Dept of Paediatrics, University of Modena, Modena, Italy.

Correspondence: J.J. Reilly, Dept of Human Nutrition, Yorkhill Hospitals, Glasgow, G3 8SJ, UK.

Fax: 441412019275

Keywords: Adenotonsillar hypertrophy doubly-labelled water method

failure to thrive

metabolic rate

obesity

Received: December 91999

Accepted after revision March 72001

The study was funded by the Royal Society and by a Leonardo Scholarship to S. Bulgarelli.
Obstructive sleep apnoea syndrome (OSAS) is common in childhood, and is often associated with failure to thrive [1-4]. The cause of failure to thrive in children with OSAS is unknown. A number of features of OSAS might predispose children to growth and nutritional problems, including increased energy expenditure, anorexia or dysphagia as a result of adenotonsillar hypertrophy and/or recurrent infection, abnormal growth hormone secretion, and nocturnal hypoxia [5-8].

Following tonsillectomy and/or adenoidectomy, growth and nutritional status tend to improve in children with OSAS. In children with failure to thrive, this may lead to a resolution of the nutritional problem [1, 4, 5, 9] while in children with OSAS who are overweight or obese, the nutritional problem typically becomes more severe [9]. These clinical observations imply that OSAS in childhood is associated with a "check" on positive energy balance, and that this check is not restricted to patients with failure to thrive, but applies across the entire spectrum of growth and nutritional status.

There is some evidence that increased energy expenditure might act as the check on positive energy balance in OSAS. MARCUS et al. [5] demonstrated substantial declines in sleeping energy expenditure (SEE) in 14 children with OSAS after adenotonsillectomy. In the absence of obvious changes in energy intake before and after surgery, MARCus et al. [5] suggested that hypermetabolism, secondary to increased work of breathing during sleep, might be responsible for failure to thrive in OSAS. STENLOF et al. [10] studied five adults with OSAS and reported that sleeping energy expenditure and 24-h energy expenditure in a whole body calorimeter were significantly increased relative to controls, and declined after treatment. Neither of these studies measured TEE, but in order to conclusively demonstrate hypermetabolism, that is to establish that any increase in SEE results in increased total energy expenditure, it is necessary to measure TEE directly in free living subjects. At present, this can only be done accurately using the doubly-labelled water method. An experiment of this kind is essential because any increase in SEE might be offset by alterations in other components of energy balance, such as reduced activity during the day $[11,12]$. Measurement of TEE has usefully identified causes of energy imbalance in a number of chronic diseases including childhood leukaemia [12, 13], human immunodeficiency virus infection [14], Rett syndrome [15] and cystic fibrosis [16]. The aim of the present study was therefore to test the hypothesis that TEE is increased in children with OSAS. 


\section{Methods}

Comparison of total energy expenditure between patients and healthy controls

TEE was measured before surgery in 11 patients. In all cases, polysomnography was used to confirm the presence of OSAS. In order to test the hypothesis that OSAS is a hypermetabolic state, TEE was compared with controls matched for age (within 12 months), sex, and season (within 2 months), using two controls for each patient with OSAS. As a further test for abnormalities in TEE in OSAS, measurements of TEE were compared against two published sources of data on childhood energy requirements; estimated average energy requirement (EAR) from UK dietary reference values [17] and empirically derived values from a published compilation of TEE measurements in childhood [18].

\section{Patients and clinical assessments}

Eleven patients (nine Caucasian, two Asian), with a clinical history of OSAS and who were on the waiting list for adenotonsillectomy were recruited (table 1). Decisions in relation to clinical management were made independently of the study. All children had been referred to an ear/nose/throat (ENT) surgeon with a history of snoring, restlessness, and periods of apnoea reported by parents during sleep. In all cases, the surgeons judged the children to have adenotonsillar hypertrophy on clinical grounds, and had listed them for adenotonsillectomy. All patients were free of other diseases relevant to their energy balance, and were not taking any medication that would have influenced their energy balance.

For the purposes of the research, the presence of OSAS was confirmed by overnight polysomnography, performed using a portable digital recording polygraphic system (Snytectics Medical, Stockholm, Sweden). Monitoring was continuous and included measurement of oxygen saturation, monitoring of oro-nasal airflow, respiratory and abdominal movements by impedance (Medtronic Synectics AB, Renstiernas Gata 12, Stockholm, Sweden), and heart rate (both by electrocardiography and from the pulse oximeter signal). Sleep states and periods of arousal were not measured. No data were obtained on hypoventilation index and neither end tidal nor transcutaneous carbon dioxide $\left(\mathrm{CO}_{2}\right)$ was measured. All sleep studies were performed and analysed by an experienced technician who was unaware of the patients condition or whether the assessment was pre- or postsurgery. Obstructive apnoeas were defined as $>6 \mathrm{~s}$ in duration. Monitoring was performed overnight during a natural sleep in hospital with sleeping times (presurgery) which ranged from $5 \mathrm{~h}$ 26 min-9 h 55 min. Before surgery, polysomnographic studies in all patients showed evidence of obstructive episodes with an apnoea index of $>1.0$ [5].

\section{Measurement of body composition and nutritional status}

In all patients and controls, body fatness and fatfree mass were estimated from total body water (TBW), assumed to be equal to the dilution space of ${ }^{18}$ oxygen $\left({ }^{18} \mathrm{O}\right)[19]$. Measurements of TBW were converted to estimates of fat-free mass using the appropriate age and sex specific "constants" for hydration of fat-free mass proposed by LoHMAN [20]

Nutritional status was assessed quantitatively using the body mass index (BMI), expressed as an SD score relative to contemporary UK reference data [21] after measurement of height to $0.1 \mathrm{~cm}$ using a portable stadiometer (Leicester Height Measure/Invitica Oadby, Leicester, UK) and weight to $0.1 \mathrm{~kg}$ in light indoor clothing using Soehule scales (Seca Alpha M770, Dusseldorf, Germany). The BMI is a simple, clinical proxy for body fatness and fat-free mass and is a useful index of "protein-energy status" [22]. Height and weight were also expressed as SD scores relative to UK 1990 reference data.

Adjustment of BMI to SD scores and use of energy

Table 1.- Characteristics of patients

\begin{tabular}{|c|c|c|c|c|c|c|c|c|c|c|c|}
\hline \multirow[t]{2}{*}{ Patient } & \multirow{2}{*}{$\begin{array}{c}\text { Age } \\
\text { yrs }\end{array}$} & \multirow{2}{*}{$\begin{array}{l}\text { Height } \\
\text { m }\end{array}$} & \multirow{2}{*}{$\begin{array}{l}\text { Height } \\
\text { SD }\end{array}$} & \multirow{2}{*}{$\begin{array}{l}\text { Weight } \\
\text { kg }\end{array}$} & \multirow{2}{*}{$\begin{array}{l}\text { Weight } \\
\text { SD }\end{array}$} & \multirow{2}{*}{$\underset{\mathrm{kg} \cdot \mathrm{m}^{-2}}{\mathrm{BMI}}$} & \multirow{2}{*}{$\begin{array}{l}\text { BMI } \\
\text { SD }\end{array}$} & \multirow{2}{*}{$\begin{array}{l}\text { Total Sleep } \\
\text { Time h }\end{array}$} & \multirow{2}{*}{$\begin{array}{c}\text { Minimum } \\
\mathrm{S}_{\mathrm{a}, \mathrm{O}_{2}} \% *\end{array}$} & \multicolumn{2}{|c|}{ Apnoea Index } \\
\hline & & & & & & & & & & Pre & Post \\
\hline 1 & 9.1 & 1.33 & -0.1 & 26.0 & -0.8 & 14.8 & -0.9 & 6.5 & 92 & 1.2 & \\
\hline 2 & 4.6 & 1.10 & 0.7 & 19.5 & 0.8 & 16.2 & -0.5 & 8.0 & 91 & 6.7 & 11.0 \\
\hline 3 & 10.2 & 1.32 & -1.2 & 25.1 & -1.7 & 14.5 & -1.1 & 7.4 & 91 & 3.2 & 5.2 \\
\hline 4 & 6.6 & 1.12 & -1.6 & 17.7 & -1.9 & 14.2 & -1.1 & 8.0 & 83 & 9.0 & 8.9 \\
\hline 5 & 3.3 & 0.88 & -2.6 & 12.0 & -2.2 & 15.5 & -0.4 & 7.0 & 78 & 6.5 & 6.0 \\
\hline 6 & 3.2 & 0.94 & -0.9 & 12.9 & -1.5 & 14.6 & -1.3 & 5.5 & 63 & 4.4 & 2.4 \\
\hline 7 & 3.4 & 1.00 & 0.4 & 20.2 & 2.2 & 20.1 & 2.6 & 7.7 & 86 & 5.4 & \\
\hline 8 & 5.8 & 1.13 & -0.4 & 27.3 & 2.1 & 21.4 & 3.0 & 6.7 & 92 & 1.2 & 1.8 \\
\hline 9 & 4.3 & 1.09 & 1.0 & 20.0 & -0.2 & 16.8 & 0.9 & 8.3 & 83 & 2.2 & 1.3 \\
\hline 10 & 6.7 & 1.07 & -2.6 & 19.5 & -1.1 & 16.9 & 0.1 & 9.0 & 88 & 5.2 & \\
\hline 11 & 5.6 & 1.11 & -0.6 & 19.9 & -0.1 & 16.1 & 0.5 & 9.9 & 87 & 2.3 & \\
\hline Mean & 5.7 & 0.91 & -0.7 & 20.0 & -0.4 & 16.5 & 0.2 & 7.6 & 85 & 4.3 & 5.2 \\
\hline SD & 2.3 & 0.12 & 1.2 & 4.9 & 1.5 & 2.3 & 1.5 & 1.2 & 8 & 2.5 & 3.7 \\
\hline
\end{tabular}

*: Oxygen saturation $\left(\mathrm{Sa}_{\mathrm{a}} \mathrm{O}_{2}\right)$ in all patients of baseline was $>95 \%$ and each patient experienced a fall of $\geqslant 6 \%$. SD: standard deviation score relative to data from [21]; BMI: Body mass index. 
expenditure per $\mathrm{kg}$ body mass minimized the effect of any differences between patients and controls.

\section{Measurement of energy expenditure}

The doubly-labelled water method was used to measure TEE over a 12/13 day period, using a protocol described elsewhere $[12,16]$. In brief, each child received a weighed, sterilized oral dose of $1.6 \mathrm{~mL} \cdot \mathrm{kg}^{-1}{ }^{18} \mathrm{O}(10 \%$ enriched $)$ that was mixed with $0.06 \mathrm{~mL} \cdot \mathrm{kg}^{-1}{ }^{2} \mathrm{H}(99.9 \%$ enriched deuterium oxide $)$. Isotopic enrichments of urines and diluted doses were measured using isotope ratio mass spectrometry (Bureau of Stable Isotope Analysis, London, UK). Total energy expenditure was calculated from disappearance rates of ${ }^{18} \mathrm{O}$ and ${ }^{2} \mathrm{H}$ using equation $\mathrm{A} 6$ of SCHOELler et al. [23] and a food quotient of 0.87 which gave an energy equivalent for $\mathrm{CO}_{2}$ production of $23.7 \mathrm{KJ} \cdot \mathrm{L}^{-1}$. Mean ratio of dilution spaces $\left({ }^{2} \mathrm{H} /{ }^{18} \mathrm{O}\right)$ was $1.05 \pm 0.02$.

\section{Statistical analyses}

Paired differences in total energy expenditure between patients and the mean of the two controls were tested for significance using a paired t-test. Energy expenditure data were expressed as $\mathrm{kJ} \cdot \mathrm{kg}^{-1} \cdot \mathrm{day}^{-1}$ for the purposes of statistical analysis. Both body mass and fat-free mass were highly correlated with TEE, and the conclusions obtained did not differ as a function of the "denominator" used to express TEE. For clarity of presentation, and ease of comparison with other studies, TEE data are described here as $\mathrm{kJ} \cdot \mathrm{kg}^{-1} \cdot \mathrm{day}^{-1}$.

\section{Results}

\section{Characteristics of patients and controls}

Characteristics of the patients (before and after surgery) are given in table 1 . None of the patients had a maxillofacial syndrome recognized as being associated with obstructive sleep apnoea (e.g. Treacher Collins or Crouzons disease).

Overnight polysomnography was carried out in all patients prior to surgery, but in only seven of the 11 patients after surgery (one moved away from the area and was lost to follow-up; two did not consent to a second polysomnographic procedure; technical failure prevented polysomnography in one other). In the seven patients with postsurgery polysomnography, apnoea index improved in three, worsened in three, and was identical to the presurgery assessment in another. Overall, apnoea index actually worsened slightly after surgery (table 1), though the change was not statistically significant (paired t-test).

Age, fat-free mass, height, weight and BMI SD scores did not differ significantly between patients and controls. Characteristics of controls are given in table 2.

Total energy expenditure: comparison between patients, healthy controls, and literature values

Data on measured TEE in patients and controls, together With TEE estimated from two literature sources, are given in table 3 . There were no significant differences in TEE between patients and controls: mean paired difference (patients minus controls) was $-14 \mathrm{~kJ} \cdot \mathrm{kg}^{-1} \cdot \mathrm{day}^{-1}, \mathrm{p}=0.43$. No significant differences were found between patients and age/sex specific estimated average requirements [17], or between patients and the compilation of literature data on age and sex-specific TEE measured by doubly-labelled water [18].

\section{Discussion}

The present study suggests that children who have OSAS, confirmed by polysomnography do not have raised TEE. TEE in patients was actually slightly lower than that of the healthy control children, but did not differ significantly from controls, and was not markedly different from literature data. In addition, it is unlikely that the levels of TEE observed in patients

Table 2. - Characteristics of controls

\begin{tabular}{|c|c|c|c|c|c|c|c|}
\hline Control & Age yrs & Height $\mathrm{m}$ & Height SD & Weight $\mathrm{kg}$ & Weight SD & $\mathrm{BMI} \mathrm{kg} \cdot \mathrm{m}^{-2}$ & BMI SD \\
\hline 1 & 10.0 & 1.39 & 0.1 & 32.2 & 0.0 & 16.7 & 3.4 \\
\hline 2 & 5.6 & 1.22 & 1.7 & 24.7 & 1.5 & 16.4 & 0.7 \\
\hline 3 & 10.0 & 1.47 & 1.4 & 41.0 & 1.4 & 18.8 & 1.1 \\
\hline 4 & 7.2 & 1.26 & 0.5 & 26.9 & 0.9 & 17.1 & 0.9 \\
\hline 5 & 3.6 & 1.03 & 0.6 & 16.1 & 0.0 & 15.2 & -0.6 \\
\hline 6 & 3.2 & 0.92 & -1.4 & 13.5 & -1.4 & 15.8 & -0.2 \\
\hline 7 & 3.7 & 1.02 & 0.3 & 16.3 & 0.1 & 15.6 & 0.4 \\
\hline 8 & 6.8 & 1.27 & 1.2 & 26.7 & 1.1 & 17.1 & 1.0 \\
\hline 9 & 4.0 & 0.98 & -1.1 & 16.9 & 0.2 & 17.6 & 1.3 \\
\hline 10 & 7.3 & 1.28 & 0.7 & 27.3 & 0.9 & 16.9 & 0.8 \\
\hline 11 & 6.8 & 1.21 & 0.0 & 25.1 & 0.8 & 17.2 & 1.0 \\
\hline Mean & 6.2 & 0.92 & 0.3 & 24.0 & 0.4 & 16.8 & 0.6 \\
\hline SD & 2.4 & 0.17 & 1.0 & 8.1 & 0.8 & 1.1 & 0.7 \\
\hline
\end{tabular}

Each entry represents the mean of two children, and no significant differences were observed between this control data and patient data (table 1); SD: standard deviation score relative to data from [21]; BMI: body mass index. 
Table 3. - Total energy expenditure $\left(\mathrm{kJ} \cdot \mathrm{kg} \cdot \mathrm{day}^{-1}\right)$ in patients and healthy controls

\begin{tabular}{lccccc}
\hline $\begin{array}{l}\text { Patient } \\
\text { control }\end{array}$ & $\begin{array}{c}\text { Patients } \\
\text { Presurgery }\end{array}$ & $\begin{array}{c}\text { Patients } \\
\text { Postsurgery }\end{array}$ & Controls & EAR & DLW \\
\hline 1 & 344 & 317 & 303 & 255 & 272 \\
2 & 342 & 392 & 318 & 364 & 339 \\
3 & 327 & 332 & 254 & 288 & 222 \\
4 & 382 & 352 & 342 & 351 & 292 \\
5 & 403 & 410 & 402 & 405 & 351 \\
6 & 293 & 297 & 323 & 405 & 351 \\
7 & 300 & 307 & 286 & 405 & 351 \\
8 & 241 & 233 & 344 & 351 & 292 \\
9 & 314 & 334 & 409 & 393 & 327 \\
10 & 311 & 330 & 362 & 368 & 292 \\
11 & 314 & & 390 & 351 & 292 \\
Mean & 325 & 330 & 339 & 358 & 307 \\
SD & 44 & 49 & 48 & 48 & 41 \\
\hline
\end{tabular}

Control values represent the mean of two control subjects, matched for age and sex. EAR: estimated age- and sexspecific average requirement for energy for each patient [17]; DLW: mean age- and sex-specific total energy expenditure from a compilation of doubly-labelled water measurements [18].

with OSAS in this study, lower than UK estimated average requirements for energy [17], would have been sufficient to produce failure to thrive or act as a constraint on growth or nutritional status [11, 17, 18].

In 10 of the 11 patients, a second measurement of TEE was obtained $\geqslant 9$ weeks after surgery (mean \pm SD $14 \pm 5$ weeks; range 9-25 weeks). The change in TEE postsurgery was $1 \pm 38 \mathrm{~kJ} \cdot \mathrm{kg}^{-1} \cdot \mathrm{day}^{-1}$ and was not significant (paired t-test). The original intention was to use each patient as his-her own control and use the change in TEE as an additional test of whether or not TEE altered as a result of surgical resolution of OSAS. Since surgery did not resolve OSAS in four of the seven patients for whom repeat polysomnography was possible, the repeated measurement of TEE did not constitute a test of the hypothesis that OSAS is associated with increased TEE. However, changes in TEE were generally small after surgery. This observation strengthens the conclusion that TEE was not abnormally high in these patients with OSAS by providing repeated measures of TEE which point to the same conclusions. In, effect repeating the TEE measurements in the presence of OSAS provided additional confidence that the TEE of these children was not abnormally high.

There are a number of possible reasons for the observation that TEE was not increased in the patients with OSAS. In general, the patients were not characterized by failure to thrive or severe OSAS. This might have diminished the ability to detect any abnormality in TEE. However, it is worth noting that surgical resolution of OSAS is generally associated with marked improvement in nutritional status across the entire range of nutritional status: even in obese patients, surgery tends to lead to more severe obesity [9]. This implies that any effect of OSAS on energy balance/growth is not restricted to children with failure to thrive, and that OSAS per se acts as a check on growth/energy balance. If this is the case, the patients should have provided an adequate test of the hypothesis that OSAS increases energy intake despite their fairly normal nutritional status. It is possible that a larger study might have revealed subtle differences in TEE between patients and controls. The original study design planned for measurements of TEE preand postsurgery to investigate changes in TEE within patients after correction of OSAS by adenotonsillar surgery. The inability to test adequately for changes after surgery in some children, because of the lack of improvement, was unanticipated. Nevertheless, data on TEE collected presurgery do not suggest any trend towards higher TEE in the patients. Finally, it is possible that the apparent absence of an increase in TEE in the patients with OSAS was due to the absence of any effect of OSAS on TEE (the null hypothesis). A number of diseases have been believed to be associated with increased TEE. The availability of accurate measurement of TEE by use of the doublylabelled water method has recently shown that many of these diseases are not "hypermetabolic" [14-16]. It is also worth noting that there are many other possible mechanisms (independent of any effect of OSAS on TEE) for the observation that OSAS acts on a "check" on growth/nutritional status in OSAS.

If $\mathrm{SEE}$ is increased in children and adults with OSAS, as has been reported [5, 10], the present findings imply that any increase in SEE is offset by a reduction in other components of energy expenditure. This might include reductions in diet-induced thermogenesis, resting energy expenditure, or, perhaps more likely, activity related energy expenditure [11]. The potential effects of OSAS on SEE and TEE are complex. Increases in SEE could be due to the energy cost of movement/arousal, the energy cost of breathing while experiencing partial or complete airway obstruction, or alterations in sympathetic nervous system activity [10]. Hypoxia might increase or decrease SEE [10]. An increase in SEE will only be "clinically" significant, that is will only increase energy "requirements", if all other components of energy expenditure remain unchanged [11]. The present data confirm that measurement of TEE, rather than just SEE or resting energy expenditure, is essential if abnormalities in energy expenditure are to be confirmed as being clinically significant $[11,12,14,16]$ : the present study suggests that the effect of OSAS on TEE is not clinically significant.

If OSAS is not associated with an increase in TEE, alternative explanations for improved growth and nutritional status after its resolution should be considered: there are many alternative hypotheses [1-8]. If the problem does have its origins in energy imbalance but hypermetabolism is ruled out, limits on energy "intake" might constrain growth/nutritional status in OSAS. Confirming this directly is problematical because of the inaccuracy and imprecision of methodology for measurement of energy intake [11]. MARCus et al. [5] reported no significant change in energy intake after successful adenotonsillectomy, but others have reported evidence of improved appetite after surgery [4, 24]. Recently, BAR et al. [25] measured changes in the IGF-1 axis before and after surgery in 10 children who had OSAS confirmed by nocturnal 
polysomnography, and found a significant increase in serum IGF-1 levels after surgery, which were associated with improvements in nutritional status. Improvements in weight SD scores observed [25] were similar to the present study, though the present study reported changes in BMI SD scores, a more sensitive indicator of energy balance since they adjust weight for height $[12,22]$. If this adjustment is not made, weight changes can be confounded by changes in height. In 7/10 patients in the present study, BMI SD score increased, and the increase overall was $0.3 \pm 0.4$, though this trend did not reach significance.

The absence of grossly abnormal energy requirements in patients with OSAS from the present study, together with recent evidence of a role for neuroendocrine disturbance [25], suggests that the cause of any "check" on growth and energy balance in children with OSAS is unlikely to be hypermetabolism. Future efforts to understand the underlying mechanism should therefore focus on the neuro-endocrine axis.

In previous studies, OSAS has not always been assessed using nocturnal polysomnography (the gold standard technique; [3, 26-28] either before or after surgery. Where nocturnal polysomnography has been used in other studies, surgery did not always abolish OSAS $[1,26,28]$. The present observation that surgery was largely unsuccessful in resolving OSAS was therefore not unique. The practical difficulties associated with nocturnal polysomnography in young children mean that in a number of previous studies it was not performed. Since many of these studies did not carry out nocturnal polysomnography on, before or after surgery, and relied on either an assumption of improved OSAS, subjective parental reports, or nap polysomnography [9], it is possible that a sizeable proportion of children studied did not have OSAS [28]. For those studies in which nocturnal polysomnography was carried out, it is likely that a proportion of children did not experience resolution of OSAS after surgery. This raises the possibility that any improvements in growth/nutritional status after surgery in earlier published reports were not due to the abolition of OSAS/increased work of breathing, but to other mechanisms, such as changes in sleep pattern.

Studies on growth, nutritional status and energy balance in obstructive sleep apnoea syndrome might have implications for other chronic respiratory diseases which are said to be characterized by increased "work of breathing". Childhood and adult obstructive sleep apnoea syndrome is an interesting model since, unlike other respiratory diseases, the putative mechanism (increased work of breathing) is potentially reversible by surgery and/or continuous positive airway pressure. In the present study, no evidence was found that increased work of breathing in children with obstructive sleep apnoea syndrome was clinically significant. This is consistent with recent evidence suggesting that the effect of increased work of breathing on energy requirements in cystic fibrosis $[11,16,29]$ and chronic obstructive pulmonary disease [30] may have been exaggerated, and with new evidence pointing to a neuro-endocrine cause of growth and nutritional problems in childhood obstructive sleep apnoea syndrome [25]. It may be worth exploring neuro-endocrine effects in other conditions where "increased work of breathing" has been considered important.

Acknowledgements. The authors are grateful to the patients, controls and their families for support, and to the staff of the Lung Function Laboratory at Yorkhill Hospital, C. King and J. Kirkpatrick, for their technical expertise and assistance.

\section{References}

1. Brouillette RT, Fernbach SK, Hunt CE. Obstructive sleep apnea in infants and children. J Pediatr 1982; 100: 31-40.

2. Guilleminault C, Korobkin R, Winkle R. A review of 50 children with OSAS. Lung 1981; 159: 275-287.

3. Mograss MA, Duchame FM, Brouillette RT. Movement/arousals: description, classification and relationship to sleep apnea in children. Am J Respir Crit Care Med 1994; 150: 1690-1696.

4. Everett AD, Koch WC, Saulsbury FT. Failure to thrive due to obstructive sleep apnea. Clin Pediatr 1986; 26: 90-92.

5. Marcus CL, Carroll JL, Koerner CB, Hamer A, Lutz J, Loughlin GM. Determinants of growth in children with OSAS. J Pediatr 1994; 125: 556-562.

6. Stradling JR, Thomas G, Warley ARH, Williams P, Freeland A. Effect of adenotonsillectomy on nocturnal hypoxaemia, sleep disturbance and symptoms in snoring children. Lancet 1990; 335: 249-253.

7. Williams EF, Woo P, Miller R, Kellman RM. Effects of adenotonsillectomy on growth in young children. Otolaryngol Head Neck Surg 1991; 104: 509-516.

8. Bate TWP, Price DA, Holme CA, McGucken RB. Short stature caused by obstructive apnoea during sleep. Arch Dis Child: 1984: 78-80.

9. Soultan Z, Wadowski S, Ra M, Kravath RE. Effect of treating OSA by tonsillectomy and/or adenoidectomy on obesity in children. Arch Pediatr Adolesc Med 1999; 153: 33-37.

10. Stenlof K, Grustein R, Hedner J, Sjostrom L. Energy expenditure in obstructive sleep apnea: effects of treatment with continuous positive airway pressure. Am J Physiol 1996; 271: E1036-E1043.

11. Reilly JJ, Edwards CA, Weaver LT. Malnutrition in cystic fibrosis: the energy balance equation. $J$ Pediatr Gastroenterol Nutr 1997; 25: 127-136.

12. Reilly JJ, Ventham JC, Ralston JM, Donaldson M, Gibson B. Reduced energy expenditure in pre-obese children treated for acute lymphoblastic leukemia. Pediatr Res 1998; 44: 557-562.

13. Warner JT, Bell W, Webb DHK, Gregory JW. Daily energy expenditure and physical activity in survivors of childhood malignancy. Pediatr Res 1998; 43: 607-613.

14. Macallan DC, Noble C, Baldwin C, et al. Energy expenditure and wasting in HIV infection. $N$ Engl $J$ Med 1995; 333: 83-88.

15. Motil KJ, Schultz RJ, Wong WW, Glaze DG. Increased energy expenditure associated with repetitive involuntary movement does not contribute to growth failure in girls with Rett Syndrome. $J$ Pediatr 1998; 132: 228-233.

16. Reilly JJ, Ralston JM, Paton JYP, et al. Energy 
balance during acute respiratory exacerbations in children with cystic fibrosis. Eur Respir J 1999; 13: 804-809.

17. Department of Health 1991. Report on Health and Social Subjects No 41. Dietary Reference Values for Food Energy and Nutrients for the UK. London, HMSO, 1991.

18. Torun B, Davies PSW, Livingstone MBE, Paolisso M, Sackett R, Spurr GB. Energy requirements and dietary energy recommendations for children and adolescents 1-18 years old. Eur J Clin Nutr 1996; 50: 537-581.

19. Reilly JJ. Assessment of body composition in infants and children. Nutrition 1998; 14: 821-825.

20. Lohman TG. Advances in body composition assessment, Monograph 3. Human Kinetics Publishers, Champaign, IL, 1993.

21. Cole TJ, Freeman JV, Preece MA. Body mass index reference curves for the UK, 1990. Arch Dis Child 1995; 73: 25-29.

22. Reilly JJ, Weir J, McColl JH, Gibson BES. Prevalence of protein-energy malnutrition at diagnosis in children with acute lymphoblastic leukemia. J Pediatr Gastroenterol Nutr 1999; 29: 194-197.

23. Schoeller DA, Ravussin E, Schutz Y, Acheson KJ, Baertschi P, Jequier E. Energy expenditure by doublylabelled water: validation in humans and proposed calculation. Am J Physiol 1986; 250: R823-R830.
24. Rosen CL. Clinical features of OSA hypoventilation syndrome in otherwise healthy children. Pediatr Pulmonol 1999; 27: 403-409.

25. Bar A, Tarasiuk A, Segev Y, Phillip M, Tal A. The effect of adenotonsillectomy on serum IGF-1 and growth in children with obstructive sleep apnea syndrome. J Pediatr 1999; 135: 76-80.

26. Davidson Ward SL, Marcus CL. Obstructive sleep apnea in infants and young children. J Clin Neurophysiol 1996; 13: 198-207.

27. Lamm C, Mandeli J, Kattan M. Evaluation of home audio tapes as an abbreviated test for OSAS in children. Pediatr Pulmonol 1999; 27: 267-272.

28. Suen JS, Arnold JE, Brooks EJ. Adenotonsillectomy for treatment of obstructive sleep apnea in children. Arch Otolaryngol Head Neck Surg 1995; 121: 525530.

29. Reilly JJ, Paton JY, Wilkinson J, Evans TJ. Adequacy of clinical formulae for estimation of energy requirements in children with cystic fibrosis. Arch Dis Child 1999; 81: 120-124.

30. Sridhar MK, Carter R, Lean MEJ, Banham SW. Resting energy expenditure and nutritional state of patients with increased oxygen cost of breathing due to emphysema, scoliosis, end thoracoplasty. Thorax 1994; 49: 781-785. 